\title{
nature
}

\section{Don't keep your distance}

\author{
Investigations that involve human subjects always require a close relationship \\ between the researchers and those being studied.
}

\rceil he US Institute of Medicine (IOM) has, in effect, directed researchers who work with human subjects to come down out of their ivory towers. The call is made in a report, issued on 19 September, that addresses the procedures that scientists should follow when they are investigating the health of underprivileged children. But the principles that it espouses apply to a great many of those involved in publicly funded research.

The IOM study was triggered by a court case involving the Kennedy Krieger Institute, a health research centre affiliated with Johns Hopkins University in Baltimore, Maryland. The institute ran into trouble during a study on the efficacy of various techniques for removing toxic lead paint from low-cost housing. Two mothers of children in the study sued the institute, claiming that the researchers never told them that their children's high levels of lead in the blood posed dangerous health risks.

In 2001, a Maryland appeals court ruled in favour of the mothers. The court criticized ethical lapses in the study, which it compared to the infamous Tuskegee experiments on black men with syphilis. It said researchers owed a "duty of care" to the children in the study and that the parents did not have the right to consent for children to participate, as the study was not going to benefit the children directly and could even cause some harm, through procedures such as blood testing. The institute subsequently reached an undisclosed financial settlement with the children's families.

The IOM report, Ethical Considerations for Research on HousingRelated Health Hazards Involving Children, makes no judgement on the Kennedy Krieger episode. But it offers some useful guidelines for managing the delicate relationship between researchers and their subjects. The Kennedy Krieger study was aimed at helping disadvantaged people, but made the subjects' families - who lived in substandard housing and had little chance of relocating - feel exploited instead. The mothers who sued the researchers claimed they were never told that their children might ingest lead, or that high blood lead levels could harm their children. The IOM points out that the signing of a consent form wasn't sufficient to ensure that the parents understood the study.

Researchers working with disadvantaged populations should become much more involved with the communities they study, the IOM report says - the time and effort that it takes to do this will be rewarded by more convincing study outcomes. Partners in the community can help researchers, it points out, by highlighting flaws in study design, recruiting participants, and strengthening the informed-consent process.

The report also suggests that poor people in the United States are becoming more wary of participating in research, after years of involvement in studies and scant indication that the findings have any real impact on their lives.

The devastation wrought by Hurricane Katrina provided a
"Poor peopleare wary of participating in research after years of involvement and scant indication that the findings have any real impact on their lives." dramatic illustration of the grounds for this mistrust. Researchers knew before the hurricane that 120,000 people in New Orleans lived in households without cars (see Nature 437, 174-176; 2005). Yet the city's evacuation plans made no provisions for these residents.

The IOM's recommendation that scientists work with communities to promote the translation of their findings into action applies in many different fields of study. Those who do basic research on rare diseases now realize, for example, that they must find unconventional ways to translate it into treatments, as drug companies have little interest in developing products for small numbers of patients.

Engaging communities is more difficult than simply publishing work and hoping that it will be noticed. But it is necessary, because science depends on public support, which in turn depends on the public's belief that research benefits them. If society comes to believe that researchers are operating in another world, divorced from real life, support for science can only be eroded.

\section{Value-free nanotech?}

\section{Efforts to gauge public attitudes to nanotechnology reveal concerns that can be readily addressed.}

$\Lambda$ profound question underlying many debates involving science and its publics is "how knowledge comes to be perceived as reliable in political settings, and how scientific claims, more specifically, pattern as authoritative".

That quote comes from Designs on Nature by Sheila Jasanoff (Princeton University Press, 2005; reviewed in Nature 437, 193-194;
2005), an overview of how the United States, Britain, Germany and the European Union have sought to deal with the issues brought up by biotechnology. Magisterial in its scope, the book takes for granted the idea, alien to many of Nature's readers, that science is not valuefree, and that some members of the public have cultural outlooks that are simply unreceptive to accounts of what science tells us.

A corollary of this is the idea, also shared by many science-studies specialists, that attempts by scientists to communicate their discipline to the public are likely to miss the point. Only by fully engaging at the outset with the cultural preconceptions of those audiences - by being what sociologists call 'reflexive' - can science's institutions do justice to their goal of engaging with citizens. At its 